\title{
LA NARRATOLOGÍA DESDE LOS AÑOS SETENTA HASTA EL SIGLO XXI
}

\author{
Dorde Cuvardic García
}

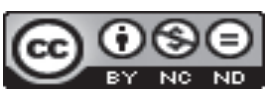

Esta obra está bajo una licencia Creative Commons

Reconocimiento-No Comercial-Sin Obra Derivada 



\title{
LA NARRATOLOGÍA DESDE LOS AÑOS SETENTA HASTA EL SIGLO XXI
}

\author{
NARRATOLOGY FROM THE SEVENTIES TO THE 21 ${ }^{\mathrm{ST}}$ CENTURY
}

\section{Dorde Cuvardic García}

\begin{abstract}
RESUMEN
En el presente artículo se explican las aportaciones que se han publicado o difundido desde 1975 sobre la figura del narrador, en el ámbito de la narratología. Don Enrique Margery publicó en el número I de la Revista de Filología y Lingüística (1 de mayo de 1975), su artículo "Alcances en torno a la problemática del narrador", en el que explicó las interpretaciones que las distintas teorías narratológicas habían ofrecido hasta entonces sobre la figura del narrador en el siglo XX. Desde esa fecha han aparecido -o se han difundido entre la crítica latinoamericana y española- propuestas tanto complementarias como alternativas. La explicación de estas últimas constituye el núcleo de este artículo: la propuesta de Norman Friedman, la sistematización de Gérard Genette, la polifonía bajtiniana, las diversas modalidades de relato paradójico, el papel y el estatuto del narrador en el discurso cinematográfico y la participación del espectador en la construcción del acto narrativo y en la estructuración de un relato semánticamente coherente.

Palabras clave: narratología, semiótica, focalización, intermedialidad, narración audiovisual.
\end{abstract}

\begin{abstract}
This article explains the contributions published and shared since 1975 about the narrator, in the field of narratology. Mister Enrique Margery published, in the first issue of the Revista de Filología $y$ Lingüística (May 1, 1975) his article "Thoughts on the Issue of the Narrator", where he explained the narratology's interpretation so far on the figure of the narrator in the 20th Century. Since then, proposals both complementary and alternative have appeared -or circulated among the Spanish and Latin American critics. These alternative proposals are at the core of this article: Norman Friedman's proposal, Gérard Genette's systematization, Bakhtin's polyphony, the several modalities of paradoxical narration, the role and status of the narrator in the film discourse and the viewer's participation in the building of the narrative act and in the forming of a semantically-coherent narration.
\end{abstract}

Key words: narratology, semiotics, focalization, intermediality, audiovisual narration.

Dr. Dorde Cuvardic García. Universidad de Costa Rica. Escuela de Filología y Lingüística. Costa Rica. Correo electrónico: dcuvardic@yahoo.es

Recepción: 16- 09- 2014

Aceptación: 19- 09- 2014 


\section{Introducción}

El narrador es una de las categorías conceptuales más antiguas de la teoría literaria. Recordemos que Platón, en el "Libro III" de La República, plantea la primera tipología de géneros de Occidente desde el eje vertebrador de la voz enunciativa (géneros de enunciación mixta, simple y pura) y que Aristóteles, en el "Parágrafo III" de su Poética, propone el llamado modo de enunciación como uno de los principales procedimientos de las imitaciones emprendidas por los seres humanos. Siglos después, esta categoría, la del narrador, encontró en el siglo XX una vía de reflexión teórica desde la narratología. Se trata de una entidad que la teoría literaria entiende desde principios antropomorfos: en principio, el enunciador de una narración es una entidad humana, un animal o una cosa revestida del atributo de emitir ideas mediante el lenguaje verbal.

El presente artículo pretende explicar algunas de las más importantes aportaciones que, sobre la categoría del narrador, han aparecido o se han difundido desde 1975. Diversas corrientes y propuestas narratológicas se han impuesto en la reflexión teórica y en la práctica de la crítica literaria desde que don Enrique Margery, en el Número 1, Volumen 1 de la Revista de Filología y Lingüística, publicara su artículo "Alcances en torno a la problemática del narrador". En este último, expone y enjuicia las distintas contribuciones que, hasta mediados de los años setenta, venía ofreciendo la narratología a la hora de comprender esta categoría que como explica Pozuelo-Yvancos (2009, p. 240), es una figura central de la teoría del relato y del pacto de la comunicación narrativa. En el presente artículo también se explicará alguna propuesta aparecida antes de este último año, 1975, pero que ha encontrado su mayor difusión en el ámbito crítico latinoamericano y español después de esta fecha.

En su artículo, don Enrique Margery explica las distintas propuestas desde un eje estrictamente cronológico, comenzando por la más antigua. A continuación se enlistan los autores, las obras y los años de aparición de estos enfoques: Percy Lubbock, The craft of fiction (1921), Jean Pouillon, Tiempo y novela (1946), Wolfgang Kayser, Interpretación y análisis de la obra literaria (1948), Wayne C. Booth, The Rethoric of Fiction (1961), Robert Stenton, Introducción a la narrativa (1965), Andrés Amorós, "Perspectiva y novela" (1967), Oscar Tacca, "La voz del narrador en la estructura narrativa" (1967), Tzvetan Todorov, "Las categorías del relato literario" (1967), y Boris Uspenski, Poétique de la composition (1970). Predominan enfoques temporalmente cercanos al momento de escritura y publicación del artículo de don Enrique Margery: uno de ellos se publicó en 1970, cinco en los años sesenta, dos en los años cuarenta, en años inmediatamente posteriores a la II Guerra Mundial, y uno en los años veinte. No debe extrañar el número de contribuciones procedentes de los años sesenta, momento de eclosión del estructuralismo y, dentro de él, de la narratología. En un apartado posterior de su artículo, titulado "Alcances a los criterios reseñados", Margery (1975, pp. 66-71) ofrece una reflexión crítica sobre los aportes y limitaciones de las propuestas mencionadas. Por sólo mencionar una de las últimas, este crítico destaca la ausencia de autores y textos latinoamericanos entre el corpus de textos literarios que emplean los teóricos mencionados a la hora de definir y elaborar sus propuestas. Además, y de manera complementaria, don Enrique Margery nos confirma el nulo desarrollo de una narratología específicamente latinoamericana a la altura de 1975. 


\section{La propuesta de Norman Friedman}

La primera teoría sobre el narrador que analizaremos y que no se comentó en el artículo de Margery es la de Friedman. Íntimamente ligado al concepto de narrador es el de punto de vista o focalización. Se parte del criterio de que todo narrador relata acontecimientos que han sido percibidos -o sentimientos que han sido experimentados- desde un punto de vista particular, focalización que le permite al narrador explicar el mundo empírico y el psicológico desde una mayor o menor amplitud de conocimiento. El "punto de vista" es importante en algunas de las teorías del narrador ofrecidas por don Enrique Margery, y en la presente ocasión explicaremos una de ellas, no aparecida en su discusión. Esta categoría estructura la tipología de Norman Friedman, sistematizada en el artículo "Point of view in Fiction. The Development of a Critical Concept", publicado en 1955 en la PMLA. Esta propuesta, aparecida antes de 1975, ha encontrado su mayor difusión en el mundo hispanohablante después de esta última fecha. Su enfoque parte del interés de responder a las siguientes preguntas, que a su vez conforman los distintos criterios que le sirvieron a Friedman para discriminar los distintos narradores de su tipología:

\footnotetext{
1) ¿Quién habla al lector? (el autor en primera o tercera persona, un personaje en primera, o ninguno de ellos?; 2) ¿Desde qué posición (ángulo) observa la historia que le cuenta? (desde arriba, desde la periferia, desde el centro, desde el frente, o fluctuante); 3) ¿Qué canales de información usa el narrador para transmitir la historia al lector? (palabras, pensamientos, percepciones o sentimientos del autor; acciones, palabras, pensamientos, percepciones o sentimientos del personaje [...]; 4. ¿A qué distancia sitúa el narrador al lector en relación con la historia? (cerca, lejos, fluctuante). (Friedman, 1955, pp. 1168-1169)
}

Friedman plantea distintos "puntos de vista" (su criterio principal para perfilar las modalidades de narradores). A continuación, se expondrán, desde una mayor subjetividad (es decir, desde una mayor presencia enunciativa del autor, en su trabajo de ordenamiento del material narrativo), en uno de los extremos, hasta una mayor objetividad (es decir, desde el mayor ocultamiento de esta última instancia), en el polo opuesto (Friedman, 1955, pp. 1169-1179):

1. Omnisciencia editorial: en este tipo de narrador o de voz predomina el relato de los acontecimientos; se utiliza poco la técnica de la escena (la descripción verbal de un acontecimiento relatado en primera persona o la exposición de una escena dialogada). Domina la voz del narrador, que adopta un punto de vista ilimitado. Es la modalidad que tradicionalmente se conoce como narrador omnisciente.

2. Omnisciencia neutral: el narrador habla en tercera persona en torno impersonal; aunque se pueden dar las escenas dialogadas (mayor cercanía del lector frente a los hechos ocurridos), la tendencia predominante consiste en que el narrador describe y relata los acontecimientos mediante su propia voz, sin evaluar explícitamente estos últimos (mayor distancia del lector frente a los hechos).

3. Yo testigo: el narrador testigo es un personaje por propio derecho que habla en primera persona, que está más o menos involucrado en la acción y que está más o menos al corriente de la conducta y la personalidad de los personajes principales; el autor delega en el narrador (personaje) testigo lo que, como observador, pueda percibir; el lector, por su parte, tiene a su disposición, únicamente, los pensamientos, sentimientos y percepciones de este narrador testigo; estrictamente, no sólo transmite este último 
el conocimiento que se origina en su actividad perceptiva, sino que también puede obtener -y transmitir- información que otros personajes le hayan proporcionado (por ejemplo, la información escrita que hayan producido estos últimos); asimismo, es común que este narrador nos informe sobre las limitaciones que sufre, en ocasiones, su acceso al conocimiento; por último, las escenas pueden ser tanto relatadas como mostradas mediante la reproducción de los diálogos (en este último caso, cuando el narrador personaje es testigo de estas escenas).

4. Yo protagonista: si pasamos del yo testigo al yo protagonista, se renuncia a cierto número de fuentes informativas y a un punto de vista más estratégico, ya que el narrador testigo, por su posición periférica frente a los acontecimientos, tiene una mayor movilidad y un mayor acceso a las distintas fuentes de conocimiento. El yo protagonista, en cambio, sólo comunica, por lo general, sus propios pensamientos, sentimientos y percepciones, por lo que su punto de vista es central y fijo, frente a la movilidad del yo testigo.

5. Omnisciencia selectiva múltiple: en esta modalidad de punto de vista desaparece el relato del narrador; todo el conocimiento es transmitido a través de la actividad mental de personajes presentes en los acontecimientos; el lector tiene acceso directo a estas mentes; enunciativamente, se procede a usar la escena (el registro externo de acciones y conversaciones, o su mediación por parte de diversos personajes, desde los que se filtran los acontecimientos) frente al relato sumario; se distingue de la omnisciencia editorial o clásica por el hecho de que mientras en la omnisciencia selectiva múltiple los pensamientos, las percepciones externas y los sentimientos se producen en presente en la mente de los sujetos perceptores, que al mismo tiempo son narradores, en la primera todos estos procesos quedan resumidos y explicados, una vez que han ocurrido.

6. Omnisciencia selectiva: es similar a la modalidad anterior, con la diferencia de que, en el presente caso, el conocimiento que obtiene el lector se limita a las percepciones, sentimientos, acciones y palabras de uno solo de los personajes; en esta modalidad, al igual que en la previa, se dramatiza la subjetividad del personaje -se muestra directamente, su discurso- y, dependiendo de la inmersión -mayor o menor- del lector en la mente del personaje, desaparecerá en mayor o menor grado la sintaxis cotidiana.

7. Modo dramático: la información que dispone el lector se limita a lo que hacen y dicen los personajes, es decir, a las acciones externas; en ocasiones, el narrador proporciona la apariencia física y el escenario en el que actúan los personajes, como ocurre en las didascalias del discurso dramático escrito; la subjetividad de los personajes -de cualquiera de ellos- puede ser inferida por los lectores, ya sea a partir de sus conductas externas o de sus diálogos.

8. "La cámara": en esta modalidad desaparece cualquier aparente selección u organización del material narrativo del autor; las convenciones descriptivas ofrecidas se orientan a ofrecer un 'slice of life', un fragmento de vida, como si transcurriera la temporalidad 
humana ante un medio de registro visual y auditivo; la realidad descrita desde esta modalidad narrativa, aunque utilice las convenciones de la objetividad, procede de una instancia autorial. El propósito es dar la impresión de que el acontecimiento sucede en vivo y en directo, en tiempo real, eliminando las marcas enunciativas del narrador.

La propuesta de Norman Friedman ha sido utilizada por críticos literarios españoles y latinoamericanos. Mencionemos uno de ellos. Albert Chillón, en su libro Periodismo y literatura. Una tradición de relaciones promiscuas (1999), emplea su tipología en el capítulo dedicado al nuevo periodismo norteamericano, escritura que of reció importantes muestras de novelas-reportajes y reportajes novelados entre los años cincuenta y los setenta. Chillón identifica, analiza e interpreta la omnisciencia editorial en The Electric Kool-Aid Acid Test (Gaseosa de ácido eléctrico), o en The Right Stuff (Lo que hay que tener), novelas reportaje del conocido Tom Wolfe; por su parte, asocia la omnisciencia neutral a las novelas reportaje de Truman Capote, Norman Mailer o Gay Talese, que evitan los juicios del narrador; el narrador testigo, que vincula con el llamado punto de vista en tercera persona -third person point of view-, término propuesto por Tom Wolfe, es empleado en León de papel (Paper Lion) (Chillón, 1999, pp. 268-293). Podríamos añadir ejemplos de cada modalidad narrativa en la literatura en español, pero por poner un solo ejemplo, la modalidad dramática se aprecia, en la literatura española, en la novela $E l$ abuelo, de Benito Pérez Galdós, totalmente dialogada.

\section{La propuesta de Gérard Genette en Figuras III y Nuevo discurso del relato}

La más relevante sistematización narratológica de las últimas décadas procede de Gérard Genette, de Figuras III (Figures III), libro aparecido originalmente en francés en 1972, dos años antes del artículo de don Enrique Margery, y publicado en español en 1989. Forma parte de una serie de estudios, de los que ya se han publicado otros cuatro volúmenes -Figuras I (Figures I), 1966; Figuras II (Figures II), 1969; Figuras III (Figures III), 1972; Figuras IV (Figures IV), 1999; y Figuras V (Figures V), 2002- dedicados a otros procedimientos y temas literarios. ${ }^{1}$ En Figuras III, el narrador queda caracterizado por diversos atributos: según el nivel narrativo desde el que relate los acontecimientos, según la posición temporal que ocupe frente a los acontecimientos relatados, según el mayor o menor conocimiento que ofrezca, según el mayor o menor grado de apropiación que realice del discurso de los personajes, etc.

En principio, para Genette, todo relato, es decir, todo acto narrativo, se hace en primera persona: "En la medida en que el narrador puede intervenir en todo momento como tal en el relato, toda narración se hace, por definición, virtualmente en primera persona.” (Genette, 1989, p. 299). Pero no se siempre se exteriorizará que el acto narrativo proceda de este última persona, ya que a veces queda implícita.

Todo narrador puede expresar o comunicar su posición temporal frente a los acontecimientos narrados. A partir de estas distintas posiciones temporales se pueden presentar cuatro tipos de narración:

ulterior (posición clásica del relato en el pasado, sin duda la más frecuente con gran diferencia), anterior (relato predictivo, generalmente en el futuro pero que nada impide conducir al presente [...]), simultánea (relato en el presente contemporáneo de la acción) e intercalada (entre los momentos de la acción). (Genette, 1989, p. 274) 
La gran mayoría de los relatos, en Occidente, tienen una temporalidad ulterior: se parte del supuesto de que los acontecimientos relatados han ocurrido en un momento cronológico anterior al momento en el que el narrador los cuenta. Narrar en pasado es un recurso que aumenta la verosimilitud del relato: se asume que los hechos se relatan una vez que han ocurrido, es decir, que el narrador ha tenido tiempo para entramarlos, para estructurarlos. Por su parte, la narración anterior o relato predictivo se da, por ejemplo, en casos en los que un narrador o personaje vaticina un acontecimiento futuro que, finalmente, termina por ocurrir. El acto narrativo, es decir, el acto de narrar, tiene lugar en un momento cronológicamente anterior al momento en que tienen lugar los hechos que comunica. A su vez, el relato simultáneo transmite la sensación de que el acto narrativo tiene lugar en el mismo momento en el que suceden los acontecimientos. Recordemos que se trata de una convención discursiva: el narrador simula relatar un acontecimiento en el mismo momento en el que sucede. La retórica antigua ya trató este procedimiento mediante el recurso del presente histórico. Por último, la narración intercalada se refiere al hecho de comunicar en ocasiones, en un relato predominantemente ulterior (narrado en pasado), que el acontecimiento es contemporáneo al acto de narrar (se relata en presente).

\subsection{Niveles narrativos extra- e intradiegéticos y narradores hetero- y homodiegéticos}

Se pueden discriminar diversos narradores a partir del nivel narrativo en el que actúen. Los narradores emiten su discurso en los llamados niveles narrativos, por lo que es necesario definir esta última categoría, aunque el teórico francés no es preciso al respecto. Según Genette (1989, p. 284), “todo acontecimiento contado por un relato está en un nivel diegético inmediatamente superior a aquel en que se sitúa el acto narrativo productor de dicho relato". Toda diégesis o relato se origina en una instancia narrativa o relatora, el narrador, cuya acción enunciativa transcurre en un nivel diegético que podemos identificar como original. El narrador del relato primero, y que protagoniza este primer acto narrativo, es extradiegético: el acto narrativo que protagonice también lo será. Por su parte, el narrador de un relato segundo que actúa en el mundo relatado por el acto narrativo inicial se conoce como intradiegético (Genette, 1989, p. 284).

Además, por su relación con la historia, también se puede presentar en los textos narrativos la modalidad del narrador heterodiegético, que no es personaje de la historia que cuenta, y la del homodiegético, narrador personaje de la historia que relata:

\footnotetext{
Así, pues, distinguiremos aquí dos tipos de relatos: uno de narrador ausente de la historia que cuenta (ejemplo: Homero en La Ilíada o Flaubert en La educación sentimental), otro de narrador presente como personaje en la historia que cuenta (ejemplo: Gil Blas o Wuthering Heights). Llamo al primer tipo, por razones evidentes, heterodiegético y al segundo homodiegético. (Genette, 1989, p. 299)
}

Además, cuando el narrador homodiegético es el protagonista del relato queda identificado como autodiegético, como es el caso de las autobiografías.

Los niveles narrativos y los tipos de narradores se pueden interrelacionar, y así ocurre en la práctica literaria, en la escritura de cuentos y novelas. El paradigma de narrador al mismo tiempo extradiegético y heterodiegético es Homero, "narrador en primer grado que cuenta una historia de la que está ausente" (Genette, 1989, p. 302). Desde el presente enunciativo, Homero relata acontecimientos pasados en los que no ha participado. Gil Blas, protagonista de la novela picaresca francesa del mismo nombre, representa un ejemplo de narrador extradiegético 
y, al mismo tiempo, homodiegético, "narrador en primer grado que cuenta su primera historia." (Genette, 1989, p. 302). Desde el presente enunciativo, cuenta en primera persona acontecimientos que él mismo ha protagonizado en el pasado. Scheherazade es el paradigma del narrador (en este caso, narradora) intradiegético y, al mismo tiempo, heterodiegético, "narrador en segundo grado que cuenta historias de las que suele estar ausente" (Genette, 1989, p. 302). En el mundo ficticio (es decir, en el mundo intradiegético relatado por el innominado narrador, quien enuncia el primer acto enunciativo, a nivel extradiegético), Scheherazade le relata al sultán cuentos sobre terceras personas. Por último, Ulises, en los Cantos IX a XII de La Odisea, es narrador al mismo tiempo intradiegético y homodiegético, "narrador en segundo grado que cuenta su propia historia." (Genette, 1989, p. 302). Las categorías genettianas estudiadas en el presente apartado han sido ampliamente incorporadas por los críticos literarios del mundo académico occidental en sus análisis e interpretaciones.

\subsection{El modo narrativo: la distancia y la perspectiva narrativa}

El llamado modo narrativo involucra dos modalidades de regulación de la información narrativa: la distancia y la perspectiva narrativa. La distancia se refiere a la posibilidad que tiene el acto narrativo de ofrecer los acontecimientos de manera más directa (mostrarlos, imitarlos, mimesis, como ocurre con las escenas dialogadas) o más indirecta (relatarlos, diégesis, donde un narrador cuenta la evolución de un acontecimiento con sus propias palabras). Esta distinción entre mostrar y relatar, recordemos, ya fue planteada por Platón en el "Libro III" de $L a$ República. Nos recuerda Gennette $(1989$, p. 221) que el filósofo griego no precisa que el relato es "más distante que la «imitación»: dice menos y de forma más mediata".

Sobre las modalidades de distancia del narrador frente a los acontecimientos relatados y sus protagonistas, Genette (1989, pp. 228-230) distingue tres: primero, el discurso narrativizado o contado, el más distante del personaje; segundo, el discurso transpuesto en estilo indirecto (en el que también se incorpora el estilo indirecto libre, una de las modalidades del estilo indirecto, cuya diferencia esencial con este último es carecer del verbo declarativo, por ejemplo, "Juan dijo que +"); y, tercero, el discurso mimético del personaje, en el que el narrador finge la cesión literal de la palabra a su personaje. En particular, aunque cuenta con precedentes en la Edad Media, el discurso indirecto libre comenzó a ser promovido a partir del siglo XIX y se hace amplio uso de este procedimiento en novelistas como Benito Pérez Galdós o Leopoldo Alas Clarín.

En cada procedimiento, si nos dirigimos del primero al tercero, veremos una mayor presencia del discurso del personaje, y una ocultación cada mayor del narrador y de la actividad organizativa del autor (en otras palabras, el narrador se acerca cada vez más al personaje, de tal manera que este acercamiento supone una visibilidad cada vez mayor del discurso de este último). En la primera modalidad, las palabras del personaje quedan mediatizadas completamente a través de las palabras del narrador; en el segundo caso, en el discurso indirecto, las palabras del personaje quedan sometidas a un menor grado de transformación por parte del narrador (es decir, se aprecia en mayor grado la voz original del personaje), mientras que en el tercer caso hay una delegación completa de la palabra del narrador, sustituida por la del personaje.

Siempre en el ámbito del modo narrativo, la segunda modalidad de regulación de la información -que surge de la elección de emplear un punto de vista más o menos restrictivoes lo que se conoce como perspectiva o punto de vista, que Genette designa con el concepto de 
focalización. El artículo de Enrique Margery ya se ocupó de esta problemática, al analizar las propuestas de Lubbock, Pouillon y Todorov sobre el punto de vista. Por lo demás, las distintas tipologías de focalización narrativa (entre ellas, la de Friedman y la de Genette) pueden ser sometidas a estudios comparativos para establecer sus semejanzas, sus diferencias y sus aportaciones respecto de la propuesta de Genette.

En primer lugar, el relato no focalizado o de focalización cero es "el que representa en general el relato clásico" (Genette, 1989, p. 244). El conocimiento ofrecido al lector está regulado por la omnisciencia del narrador. Encuentra su equivalencia en aquellos relatos que "Todorov simboliza mediante la fórmula Narrador > Personaje (en que el narrador sabe más que el personaje o, dicho con mayor precisión, dice más de lo que sabe personaje alguno)" (en cursiva en el original) (Genette, 1989, p. 244). Es lo que ocurre, por ejemplo, con el narrador de La Regenta, de Leopoldo Alas (Clarín), y en muchas novelas del realismo decimonónico. En segundo lugar, la narración puede ofrecer una focalización interna, donde todo el conocimiento comunicado al lector procede de la subjetividad del personaje perceptor (el narrador comunica su mundo psicológico y perceptivo). Esta focalización puede ser:

\begin{abstract}
ya sea fija (ejemplo canónico: Los embajadores, en el que todo pasa por Strether o, mejor aún, Lo que sabía Maisie, en el que no abandonamos casi nunca el punto de vista de la niña, cuya «restricción de campo» es particularmente espectacular en esa historia de adultos cuyo significado no entiende), variable (como en Madame Bovary, en que el personaje focal es primero Charles después Emma, luego de nuevo Charles o, de forma mucho más rápida e inasible, en Stendhal) o múltiple, como en las novelas epistolares, en que se puede evocar el mismo acontecimiento varias veces según el punto de vista de varios personajes epistológrafos. (Genette, 1989, p. 245)
\end{abstract}

Siguiendo la fórmula de Todorov, el narrador que transmite un conocimiento fundamentado en la focalización interna sabe lo mismo que el personaje y este saber del individuo es el conocimiento que llega a comunicar al lector. Se expresa en Todorov mediante la fórmula Narrador=Personaje. La focalización interna puede ser fija, variable o múltiple; en el primer caso, la información ofrecida procede de un solo personaje, y en el segundo y tercer caso, de varios (el relato tendrá un protagonista colectivo). Se busca ofrecer, mediante sus propias palabras, las percepciones y las reflexiones procedentes de la conciencia de un sujeto que trata de comprender su mundo circundante. Su manifestación discursiva más pura se canaliza a través del monólogo interior de aquellos personajes (Genette, 1989, p. 247) que percibiesen la realidad exterior y experimentaran sus sentimientos y sus emociones desde sus propias individualidades.

Si nos acercamos al artículo de Victor Shklovski, "El arte como artificio" (1917), nos daremos cuenta que el procedimiento de la enunciación excéntrica o periférica -que expone a través del relato Jolstomer, de Tolstoi, enunciado por un caballo-, uno de los típicos procedimientos de desfamiliarización, extrañamiento, distanciamiento o singularización, se apoya básicamente en el uso de la focalización interna. Se desfamiliariza la percepción y la comprensión del mundo, es decir, se aprecia novedosamente, cuando la realidad es percibida desde la Otredad, desde el observador que no se involucra en los acontecimientos. Son innumerables las enunciaciones excéntricas que utilizan la focalización interna, ya sea fija, variable o múltiple: el sujeto exótico de la novela epistolar del siglo XVIII, el objeto enunciador (la celosía, en la novela del mismo nombre de Robbe-Grillet) o el animal que enuncia el acontecer humano; el flâneur (frente al simple transeúnte), el extranjero (frente al nativo) o el campesino (frente al urbanita), personajes todos ellos que, en el costumbrismo y desde la primera persona, aprecian la Nación o la ciudad desde una perspectiva reflexiva. 
Por último, la narración puede utilizar la focalización externa, en la que, como sucede con las novelas de Dashiel Hammett, el personaje protagonista actúa sin que el lector conozca sus pensamientos ni sus sentimientos; asimismo, se utiliza en las novelas de intriga y en las de aventuras (en este último caso, sobre todo en las primeras páginas) (Genette, 1989, p. 245), como mecanismo de suspense. La focalización externa también es propia del relato behaviorista. Desde Todorov se formularía como aquel relato en el que el narrador comunica menos de lo que sabe el personaje (Genette, 1989, p. 244), ya que sólo informa sobre la actividad perceptiva de este último, sin que se transmita ninguna información sobre sus experiencias mentales, es decir, intelectuales y emotivas.

Es necesario reproducir dos precisiones planteadas por Genette. La primera radica en que "la fórmula de focalización no se aplica siempre a una obra entera, sino más bien a un segmento narrativo determinado, que puede ser muy breve. Por otra parte, la distinción entre los diferentes puntos de vista no siempre es tan clara como podríamos creer, si sólo tuviéramos en cuenta los tipos puros" (Genette, 1989, p. 246). En realidad, toda tipología, cuando se aplica a los casos empíricos, se encuentra sujeta a este mismo tipo de consideraciones.

Han comenzado a proliferar en los últimos cuarenta años las investigaciones centradas en las focalizaciones que los narradores llegan a utilizar a la hora de comunicar conocimiento sobre el mundo ficcional. Entre ellas podemos destacar a Jost (2002) y a Peña-Ardid (1999), quienes han estudiado los procesos de auricularización (transmisión del conocimiento percibido a través del oído del personaje) y de la ocularización (transmisión del conocimiento percibido visualmente, por medio del ojo) en la narrativa literaria y cinematográfica. La transcripción exteriorista de la actividad perceptiva es típica del lenguaje cinematográfico y de su punto de vista 'objetivista'. Es un medio que utiliza, predominantemente, la focalización típicamente externa de la cámara. Por asociación con este último lenguaje, diversos autores del siglo XX han adoptado la auricularización y la ocularización como modalidades de registro de la actividad perceptiva de sus personajes, en el marco de un trasvase consciente de procedimientos cinematográficos a la práctica literaria.

Cabe la posibilidad de que tanto el narrador homodiegético como el heterodiegético utilicen una focalización cero, externa o interna. Es decir, voz y focalización se dan conjuntamente en la práctica del texto narrativo. Genette, en Nuevo discurso del relato, publicado originalmente en francés en 1983, llega a estructurar hasta 5 modalidades de lo que define como situación narrativa, resultante de combinar una voz y una focalización. Basándose en Genette, Pozuelo-Ybancos (2009, pp. 266-267) formula ejemplos de cada una de estas situaciones narrativas: La Regenta, de Clarín, es un ejemplo de relato heterodiegético de focalización cero; Trafalgar, de Galdós, de relato homodiegético de focalización cero; La Metamorfosis, de Kafka, de relato heterodigético de focalización interna; El Lazarillo, de relato homodiegético de focalización interna; y, por último, El Jarama, de Rafael Sánchez Ferlosio, de relato heterodiegético de focalización externa.

El narrador de La Regenta no emite su voz desde el mundo ficcional de Vetusta, pero tiene la capacidad de describir tanto el mundo físico como el psicológico de los vetustenses, por lo que utiliza la focalización cero. Por su parte, el narrador de Trafalgar actúa en el mundo ficcional, ya que es un grumete que participa en la famosa batalla que da título a la novela, pero comunica al lector incluso escenas a las que no ha asistido como espectador (recordemos que en la focalización cero el narrador comunica mayor conocimiento de lo que cualquier personaje específico está en capacidad de saber). En La metamorfosis, el narrador no vive en el mundo 
ficcional, y por lo tanto narra acontecimientos protagonizados por terceros, pero no deja por ello de relatar, exclusivamente, al inicio de la novela, las sensaciones y las reacciones que experimenta Gregorio Samsa al convertirse en un insecto, por lo que se utiliza la focalización interna. En El Lazarillo de Tormes, el narrador en primera persona sólo relata acontecimientos que ha conocido de primera mano, que ha protagonizado o de los que ha sido testigo, filtrados por su conciencia, por lo que también utiliza la focalización interna. Por último, en El Jarama, el narrador, que no vive en el mundo ficcional, sólo relata acontecimientos externos, sin adentrarse en la psicología de los personajes, por lo que la focalización es externa.

Genette (1989, pp. 309-310) también se ocupa de las funciones que puede asumir un narrador: la más evidente es la de contar o relatar una historia integrada por acontecimientos (función narrativa); el narrador también puede referirse al mismo texto narrativo, para resaltar, por ejemplo, su organización interna (función de control); se puede centrar en establecer comunicación con el narratario, con lo que se resalta la situación narrativa misma, como sucede en las novelas epistolares (función comunicativa); por último, el narrador se puede orientar hacia sí mismo y explicar el tipo de vínculo que guarda con los acontecimientos narrados, ya sea que simplemente los testimonie (función testimonial) o, más bien, los evalúe (función ideológica).

Desde los años ochenta, en España y Latinoamérica, se han publicado innumerables estudios de crítica literaria y medial que utilizan la propuesta de Gérard Genette aparecida en Figuras III como fundamento conceptual y metodológico. En particular, numerosos manuales de teoría literaria han incorporado esta propuesta en el capítulo dedicado a la narratología (véase, por ejemplo, Pozuelo-Yvancos, 1992).

\section{La narratología desde la polifonía bajtiniana}

Cuando se considera el discurso literario desde la polifonía bajtiniana, podemos descubrir que este enfoque permite explicar algunas de las funciones típicas del narrador. La polifonía se puede identificar en la presencia de distintos enunciadores en una narración: narradores, personajes o voces ajenas. El dialogismo se aprecia en el hecho de que cada una de estas voces puede incorporar, tanto en el plano estilístico como ideológico, cualquiera de las demás voces. En este sentido, por ejemplo, se pueden presentar diversos grados de imbricación entre la voz del narrador y la voz de los personajes (discurso indirecto libre, por ejemplo). El dialogismo también se aprecia en la incorporación, en el acto enunciativo de la voz narradora, de voces ajenas (la opinión pública, la voz de un crítico, de un político, etc.). Más o menos directamente, el narrador puede responder, con distintos procedimientos, a las diversas voces, previamente expresadas en la sociedad, de las que se apropia: puede utilizar, por ejemplo, la estilización paródica, mediante la que el narrador se burla del estilo y la ideología de otro hablante. A su vez, las palabras elegidas, la estructura del acto narrativo, el tema propuesto, son áreas del enunciado que el narrador elegirá con todo detalle al anticipar la respuesta del destinatario: en el marco de cualquier circuito comunicativo, la actitud cooperativa o confrontativa frente a sus posibles destinatarios determinará la estructura del enunciado que planifique el enunciador.

En el capítulo III, titulado "El plurilingüismo en la novela", de Problemas literarios y estéticos, Bajtín (1986) considera que la novela humorística (visible en Inglaterra, por ejemplo, en Fielding, Stern, Dickens o Thackeray) es la forma más ostensible de plurilingüismo en este género, ya que el autor, desde la enunciación del narrador, recrea paródicamente -en lo que se conoce como estilización paródica - diversos formatos discursivos, como son la elocuencia parlamentaria, 
la elocuencia jurídica, el protocolo parlamentario o judicial, el discurso periodístico o el lenguaje de los negocios (Bajtín, 1986, p. 130). Además, en lo que este crítico llama construcción pseudoobjetiva apreciamos la técnica del estilo indirecto libre, procedimiento que, desde la perspectiva bajtiniana, es dialógico. Recordemos que consiste en la apropiación de las palabras del personaje desde el discurso del narrador: el acto enunciativo del narrador incorpora el acto enunciativo de los personajes. Esta construcción pseudo-objetiva o estilo indirecto libre es explicada por Bajtín al final del capítulo "El plurilingüismo en la novela".

La narración transcultural es un término equivalente al de polifonía narrativa. En novelas como Don Segundo Sombra o La vorágine aparecen distintos registros de habla en los personajes, pero ninguno de ellos se integra al estilo del narrador. Este último no incorpora el habla dialectal de los personajes, es decir, los registros de habla de la sociedad representada. No se puede hablar propiamente, en los casos mencionados, de novelas polifónicas. Una novela dialógica sería aquella, más bien, en la que el estilo y la ideología del narrador quedasen determinados parcialmente, cooperativa o conflictivamente, por el estilo y la ideología de los personajes cuyas acciones relata. Schwartz (1976, pp. 427-446) ha demostrado que Don Segundo Sombra es una novela monológica: el narrador homodiegético, ya adulto, utiliza un registro de habla distinto al usado por él mismo, como personaje adolescente, en su relato retrospectivo.

\section{El narrador en la teoría narratológica cinematográfica}

El término mismo "narrador" se vuelve problemático en su aplicación a la enunciación cinematográfica por la condición antropomorfa bajo la que ha sido conceptualizado. La enunciación cinematográfica, como instancia de la que se origina el discurso, no exhibe ningún atributo humano. La manera más tradicional a la hora de identificar al narrador en una película ha consistido en establecer su identidad absoluta con la actividad de registro de los acontecimientos de la cámara. Esta última sería el ojo de un narrador que, a pesar de sus atributos antropomorfos, no queda visualizado o mostrado ante los espectadores, dentro del encuadre cinematográfico.

El cine, al igual que el teatro, se caracteriza por ofrecer un modo de enunciación, como diría Aristóteles, basado en el mostrar, en escenificar, en representar, frente al relatar (mímesis frente a diégesis). Por este motivo, el narrador no es una 'voz' tan 'evidente' en el cine, como sí lo es en la novela y en el cuento. En consecuencia, la posibilidad y el estatus del narrador ha sido problematizado en el discurso cinematográfico. Dado que no aparece ninguna persona gramatical que se identifique a sí misma como fuente del acto discursivo, los investigadores han tratado de discriminar la 'existencia' de un narrador cinematográfico, por lo general, no sólo a partir de la actividad de la cámara, sino también a partir de los procedimientos mediante los que se organizan las elecciones paradigmáticas y sintagmáticas de este discurso, es decir, a partir de los procedimientos de organización del relato. La problematización de la noción de narrador por los teóricos del lenguaje cinematográfico ha sido explicada por Jost con claridad:

\footnotetext{
$\mathrm{Si}$, como a menudo se ha dicho, la imagen en movimiento no conoce sino un único tiempo, el presente, no hay que sorprenderse de que a veces se le niegue al cine la posibilidad de ser un relato de pleno derecho. En efecto, ante la casi imposibilidad de introducir una distancia entre el acto de narrar y lo narrado, la imagen parece ir más allá del relato y alcanzar directamente lo real [...]. Contrariamente a la literatura, que es capaz de introducir una distancia entre el tiempo de la diégesis y el tiempo de la narración, [...] diégesis y relato se confunden (pero ¿por quién?) de suerte que me es muy difícil identificar una instancia narrativa. (Jost, 2002, p. 53)
} 
El cine clásico o realista prefiere borrar cualquier manifestación textual de un posible enunciador o narrador, frente al cine experimental, que con sus estrategias de reflexividad o distanciamiento pretende textualizar -incorporar en el texto cinematográfico- la existencia de una instancia enunciadora, la que organiza el discurso. Si bien parte del cine moderno (dígase, vanguardista, experimental) prefiere mostrar huellas textuales de la enunciación, el cine clásico, dígase realista, se esfuerza en borrarlas "para destacar lo que les sucede a los personajes o lo que relatan narradores explícitos y «actorializados»" (Gaudreault y Jost, 1995, p. 54).

Al final del Capítulo 4, "Principios de la narración", Bordwell dedica un apartado a la figura del narrador, en el que plantea la siguiente pregunta: “¿En qué medida podemos hablar de un narrador como fuente de la narración?” (Bordwell, 1996, pp. 61-62). En el discurso fílmico caben diversas posibilidades. En primer lugar, el personaje de una película de ficción puede ser un narrador (en este caso hablamos de personaje narrador): este último narra acciones de la historia (Bordwell, 1996, p. 61). En una segunda posibilidad, una persona que no forma parte de la historia queda identificada como fuente informativa en algunas partes de la narración, ya sea como una voz over que comenta el mundo diegético, ya sea como un maestro de ceremonias que comenta -dirigiéndose al espectador- este último mundo, sin que intervenga en él; son, en todo caso, narradores engullidos finalmente por el proceso narrativo global del filme en su conjunto (Brodwell, 1996, pp. 61-62).

Cabe una tercera posibilidad, la de un narrador implícito no personificado, que en el ámbito de la literatura ha sido propuesto por Wayne Booth en Retórica de la ficción desde la categoría del autor implícito. En la teoría cinematográfica ha sido etiquetado como el gran imaginador, propuesto por Albert Laffay en La lógica del cine: creación y espectáculo (Logique du cinéma: Création et spectacle) en 1964. Así, por ejemplo, Casetti y di Chio (1991, pp. 227-228) prefieren designar como narrador de un filme al conjunto de marcas o huellas del llamado autor implícito que se puedan reconocer en el discurso, es decir, la propuesta ideológica y estética del enunciador que se pueda inferir a partir del texto fílmico, tomando como punto de partida el análisis de sus procedimientos, el trabajo de organización del relato; así, con Ciudadano Kane como ejemplo ilustrativo, son 'huellas' o 'marcas' del narrador, entre otros, los símbolos de la emisión o de la producción de imágenes que aparecen en la fícción (espejos, ventanas, pantallas), las soluciones estilísticas empleadas (como el travelling), o la alta frecuencia con la que aparecen personajes que asumen papeles de informadores, al relatar la vida de Charles Foster Kane.

David Bordwell somete a crítica la aplicación al discurso cinematográfico de la categoría de autor implícito como narrador no personificado, y pasa, finalmente, a explicar cómo entiende el concepto de narrador. Para Bordwell, tanto el narrador extradiegético no personificado (asimilable al trabajo de la cámara) como el autor implícito -las huellas autoriales en la organización del discurso- no tienen relevancia, no son figuras operativas, en el discurso cinematográfico:

\footnotetext{
Puesto que cualquier declaración puede construirse con respecto a una supuesta fuente, la teoría literaria puede justificarse buscando una voz hablante o un narrador. Pero al ver una película, raras veces somos conscientes de que una entidad similar a un ser humano nos cuenta algo. [...] En cuanto al autor implícito, esta construcción no añade nada a nuestro entendimiento de la narración fílmica. Al autor implícito de un filme no podemos asignarle ningún rasgo que no pueda, de forma más simple, adscribirse a la propia narración: ésta, a veces, suprime información, limita nuestro conocimiento, genera curiosidad, crea un tono, etc. Otorgar a cada película un narrador o un autor implícito es permitirse una ficción antropomófica. (Bordwell, 1996, p. 62)
} 
Como se puede apreciar, Bordwell prefiere limitar el papel y la relevancia de la figura del narrador -por lo menos, de su definición tradicional, antropomorfa y procedente de la teoría literaria, en el discurso cinematográfico-. Se trata de una perspectiva pragmática, fundamentada en la activación de hipótesis interpretativas a confirmar o refutar por el espectador. Explica que

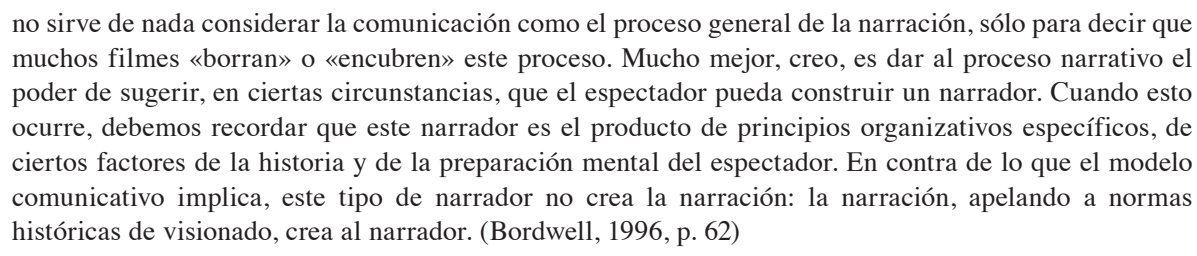

En las últimas décadas ha aparecido un acercamiento al relato como un conjunto de operaciones cognitivas que el lector (cuento y novela) y el espectador (relato cinematográfico) elaboran al enfrentarse al texto. Podría considerarse a David Bordwell próximo a este último acercamiento en la propuesta que ofrece en La narración en el cine de ficción (1985, primera edición en inglés; 1996, primera edición en español). Aquí se interpreta la narración como un constante trabajo interpretativo, realizado por el espectador, de confirmación o refutación de las expectativas, al mismo tiempo que el personaje, en la ficción, confirma o refuta las hipótesis que formuló previamente a la hora de interpretar el mundo que percibe.

A pesar de propuestas como la de Bordwell, recordemos que la narratología literaria -y la categoría de narrador- ha tenido un papel relevante, por lo menos como punto de partida, para el inicio del estudio narratológico de otros tipos de relatos, como el cinematográfico o el del cómic, que utilizan otros medios expresivos. El apoyo que ha tenido la narratología cinematográfica en la literaria, es decir, el trasvase conceptual realizado desde la segunda hacia la primera, no es un proceso raro en la semiótica. Recordemos que la lingüística ejerció un imperialismo teórico en esta última disciplina a partir de los años sesenta, como destacó Barthes (1962, p. 20) en su momento en "Elementos de semiótica", artículo en el que este investigador tenía por objetivo, "desgajar de la lingüística conceptos analíticos, de los que se piensa a priori que son suficientemente generales como para permitir esbozar la investigación semiológica". Lo mismo podemos decir de la relevancia de la narratología literaria en el estudio (análisis e interpretación) de todo tipo de relatos, cuyos recursos conceptuales se han utilizado en la investigación de narraciones no estrictamente literarias. Así, han aparecido innumerables libros de análisis e interpretación cinematográfica dedicados a la narratología audiovisual que han tomado como base la literaria, como El relato cinematográfico. Cine y narratología, de André Gaudreault y Francois Jost. En esta contribución francesa, el referente teórico que estructura el capítulo dedicado a la narratología es Gérard Genette, como también ocurre en El ojo-cámara. Entre film y novela, de Francois Jost, o en Nuevos conceptos de la teoría del cine, de Robert Stam, Robert Burgoyne y Sandy Flitterman-Lewis.

\section{El narrador en las distintas modalidades de relato paradójico}

También deben dedicarse reflexiones a la actividad del narrador en el estudio de las diversas modalidades del relato paradójico, en el que se subvierten los principios del relato realista tradicional. En la Universidad de Hamburgo, y bajo la dirección de Klaus Meyer Minneman, se desarrolló en la primera década del presente siglo el proyecto "Transgresiones 
paradójicas de planos ontológicos y de comunicación en textos literarios narrativos: los recursos de la mise en abyme, metalepsis, meta/hipo y pseudodiégesis", cumplido por el Grupo de Investigaciones Narratológicas de la mencionada universidad. Algunos de sus resultados se ofrecen en la compilación La narración paradójica. 'Normas narrativas' y el principio de la transgresión (2006), donde se proponen diversas modalidades de este tipo de narrativa, en algunas de las cuales interviene la figura del narrador. En cada una de ellas se pueden dar diversas submodalidades, por lo que, para no detenernos demasiado en su explicación, nos limitaremos a las más pertinentes para estudiar, desde el relato paradójico, la figura del narrador.

Una de ellas es la silepsis, procedimiento basado en el principio de la contigüidad. En el ámbito de la anulación paradójica de límites, surge cuando, en la ficción, "se produce, debido al modo de la narración, una nivelación entre el mundo de la narración y el mundo narrado, o también entre los diferentes tiempos y espacios de la narración misma" (MeyerMinnemann, 2006, p. 55). Uno de sus procedimientos más empleados es el de la interrupción del mundo narrado por el narrador, y esta interrupción queda incorporada -mencionada- en el texto, como ocurre al final de la aventura del vizcaíno en la I Parte de El Quijote, donde el narrador-autor se disculpa al detener el relato de los acontecimientos por carecer de su continuación. ¿En qué consiste el efecto paradójico de este procedimiento? Resulta "del paro abrupto del fluir del tiempo narrado como si [...] estuviera al alcance de la mano del narrador capaz de detenerla [la historia]" (Meyer-Minnemann, 2006, p. 56). El narrador relata acontecimientos que han ocurrido en el pasado, y la silepsis, al 'simular' que el narrador interrumpe un acontecimiento, convierte ambos momentos, cronológicamente separados (el acto de narrar y la acción narrada) en temporalmente simultáneos. También se da la silepsis cuando, abruptamente, sin solución de continuidad, una narración pasa de utilizar un narrador homodiegético a otro heterodiegético, y viceversa (Meyer-Minnemann, 2006, pp. 56-57).

Por su parte, la epanalepsis, cuyo principio rector es la anulación de límites, cubre lo que se conoce como puesta en abismo, así como los procedimientos de serialización o repetición; en este último caso, el de la repetición, distintos narradores de un mismo nivel diegético pueden relatar una sola historia mediante distintos relatos o, por el contrario, un narrador puede relatar una sola historia de distinta manera (Lang, 2006, pp. 36-37). En el ámbito específico de la puesta en abismo, en el que el narrador relata una historia en la que, a su vez, se relata una historia que guarda afinidades temáticas y argumentales con la primera, debe mencionarse el importante estudio de Dallenbach, El relato especular, publicado en español en 1991, cuyo original en francés, aparecido en 1977, lleva por título Le recit speculaire: essai sur la mise en abyme.

La metalepsis es una modalidad de relato paradójico que también puede involucrar la intervención del narrador. Genette se ha ocupado de este procedimiento en Figuras III (donde utiliza el ejemplo de "Continuidad de los parques", de Cortázar) y, asimismo, le ha dedicado un libro, titulado Metalepsis. De la figura a la ficción, publicado en español en el 2004. Su principio rector es la ruptura de los límites narrativos, en términos espaciales y temporales. Ocurre, por ejemplo, cuando un narrador homodiegético irrumpe en el relato de un narrador heterodiegético, como sucede al final del cuento "Segunda vez", de Cortázar, o cuando la narración autodiegética designa al inicio del relato a un narrador humano y, después de un momento de transición, pasa a designar a un narrador no humano, como sucede en "Axolotl", también de Cortázar. Ambos ejemplos son analizados por Meyer-Minnemann (2006, pp. 61-62). 
Por último, la hiperlepsis - basada en el principio de la superposición- también ha sido propuesta como modalidad de relato paradójico. Se supone que el discurso de un narrador y el de un personaje no se pueden superponer o fusionar, ya que proceden de orígenes distintos. El estilo indirecto libre -mediante el que el narrador expresa con sus propias palabras el discurso del personaje- se salta estos límites:

\footnotetext{
De la superposición paradójica de dos situaciones de enunciación en el discurso indirecto libre resulta que el discurso del narrador, que reporta el discurso de su personaje, viene a ser al mismo tiempo el discurso del personaje sin por eso dejar de ser el discurso del narrador. Es así como se transgrede, borrándolo, el límite entre dos situaciones de enunciación distintas cuya función, según la doxa narrativa en general, consiste en hacer distinguible la procedencia de diferentes discursos existentes en un relato de ficción. (Meyer-Minnemann, 2006, p. 64)
}

De la misma forma que las categorías de la narratología tradicional nos permiten analizar el relato realista, las categorías del relato paradójico posibilitan al crítico literario comprender el funcionamiento de muchas narraciones postmodernas. Recordemos que la postmodernidad literaria tiene en la disolución de la distinción entre realidad y ficción uno de sus más importantes objetivos, y esta anulación se da, como es evidente, mediante los recursos del llamado relato paradójico, si se toma como criterio de comparación la narración de la realidad tradicional, que respeta los límites especiales, temporales y ontológicos.

\section{Conclusiones}

Las principales corrientes teóricas -surgidas o difundidas desde los años setenta- que explican la categoría del narrador, son las siguientes; la sistematización de Gérard Gennete (que ofrece una propuesta de gran éxito crítico, tanto en el ámbito anglosajón como en el español y latinoamericano), la lenta incorporación de la propuesta de Norman Friedman a la crítica española e hispanoamericana, y la narratología orientada hacia el proceso interpretativo del lector o del espectador. Además, se ha profundizado en el estudio de la aspectualización o focalización, al indagarse en sus distintas modalidades, como son la auricularización y la ocularización. Además, desde los años setenta se aprecia un mayor interés por las posibilidades y limitaciones de la noción de narrador en el discurso cinematográfico y se han establecido sus diferencias frente al narrador antropomorfo procedente de la literatura. Asimismo, la consideración del narrador desde el dialogismo bajtiniano (el narrador en su actividad de respuesta a enunciados ajenos, o la incorporación de la voz del personaje en la voz del narrador) es otra productiva área de estudios de las últimas décadas. Por último, se ha concedido mayor importancia al papel del narrador en la construcción de diversas modalidades de relato paradójico, típico en la práctica de escritura postmoderna, que procura anular las convenciones del relato realista.

\section{Notas}

1. Solamente Figuras III y Figuras $V$ han sido traducidos y publicados en español.

\section{Bibliografía}

Amorós, A. (1967). Perspectiva y novela. Historia y estructura de la obra literaria. Madrid: Consejo Superior de Investigaciones Científicas. [Anejos de la Revista de Literatura. 31, 140-157]. 
Aristóteles. (1994). Poética. Barcelona: Icaria.

Bajtín, M. (1986). Problemas literarios y estéticos. La Habana: Editorial Arte y Literatura.

Booth, W.C. (1961). The Rethoric of Fiction. Chicago: University of Chicago Press.

Bordwell, D. (1996). La narración en el cine de ficción. Barcelona: Paidós.

Chillón, A. (1999). Literatura y periodismo. Una tradición de relaciones promiscuas. [Prol. M. Vázquez-Montalbán]. Servei de Publicaciones. Barcelona: Universitat Autònoma de Barcelona.

Dallenbach, L. (1991). El relato especular. Madrid: Visor.

Friedman, N. (1955). Point of View in Fiction: Development of a Critical Concept. PMLA. 70, $1160-1184$.

Genette, G. (1989). Figuras III. Barcelona: Lumen.

Genette, G. (2004). Metalepsis. De la figura a la ficción. México: Fondo de Cultura Económica.

Jost, F. (2002). El ojo-cámara. Entre film y novela. Buenos Aires: Editorial Catálogos.

Kayser, W. (1970 [1948]). Interpretación y análisis de la obra literaria. (4 ${ }^{\text {ta }}$ ed.). Madrid: Gredos.

Lubbock, P. (1972 [1921]). The craft of fiction. (30 ed.). New York: The Viking Press

Margery-Peña, E. (1975). Alcances en torno a la problemática del narrador. Revista de Filología y Lingüística. 1 (1), 55-82.

Meyer-Minnemann, K. (2006). Narración paradójica y ficción. Por: N. Grabe, S. Lang y Meyer Minnemann (Eds.). La narración paradójica y el principio de la transgresión. (49-71). Madrid: Iberoamericana.

Peña-Ardid, C. (1999). Literatura y cine: una aproximación comparativa. Madrid: Cátedra.

Pozuelo-Yvancos, J.M. (1992). Teoría del lenguaje literario. Madrid: Cátedra.

Pouillon, J. (1970). Tiempo y novela. Buenos Aires: Paidós.

Stanton, R. (1969 [1965]). Introducción a la narrativa. Buenos Aires: Carlos Pérez editor.

Tacca, O. (1967). La voz del narrador en la estructura narrativa. Historia y Estructura de la Obra Literaria. Madrid: Consejo Superior de Investigaciones Científicas. [Anejos de la Revista de Literatura. 31, 137-157].

Tzvetan T. (2001 [1967]). Las categorías del relato narrativo. Por: R. Barthes (Ed.). Análisis estructural del relato. (161-197). (5 ${ }^{\text {ta }}$ ed.). México: Ediciones Coyoacán.

Uspenski, B. (1972 [1970]). Poétique de la composition. Paris: Editions du Seuil.

Valles-Calatrava, J.R. (2008). Teoría de la narrativa. Una perspectiva sistemática. Madrid: Iberoamericana.

Vayone, F. (1996). Guiones modelo y modelos de guión. Argumentos clásicos y modernos en el cine. Barcelona: Paidós. 